\title{
Presepsin and Resistin as Diagnostic Markers for Bacterial Infection in Patients with Decompensated Cirrhosis
}

\author{
Mahmoud Ahmed Sharafeddin ${ }^{1}$, Amany Mohammed Abd Allah ${ }^{2}$ \\ Ahmed Abdelrahman ${ }^{1}$ \\ ${ }^{1}$ Department of Internal Medicine, Faculty of Medicine, Zagazig University, Egypt. \\ ${ }^{2}$ Department of Family Medicine, Faculty of Medicine, Zagazig University, Egypt.
}

Corresponding Author Amany Mohammed Abd Allah

Mobile:

(+02) 127620881

E mail:

dr.amanymohammed@ gmail.com

Key words: Infection, decompensated, diagnostic, accuracy
Background and study aim: Bacterial infections mess up prognosis of cirrhotic patients. Presepsin and resistin are favorable infection markers that can help in diagnosis of such condition. This study aimed to assess performance of presepsin and resistin in diagnosis of infection compared with $\mathrm{C}$ reactive protein (CRP) and procalcitonin (PCT) among patients with decompensated cirrhosis.

Patients and Methods: Two hundred and thirteen patients with decompensated cirrhosis admitted to Internal Medicine hospital, Zagazig University, were included in this study. All patients underwent history taking, thorough clinical examination and laboratory investigations including measuring CRP, PCT, presepsin and resistin.

Results: About $47 \%$ of patients have infections. Presepsin and resistin were significantly higher among patients with infection and positively correlated with Model for End-stage Liver Disease score

\section{INTRODUCTION}

Bacterial infections occur in up to one quarter of hospitalized decompensated cirrhotic patients [1]. Infectious agents trigger inflammatory response that causes progression of liver failure and development of complications; hence increases morbidity and mortality [2].

The diagnosis of having bacterial infections can be established upon clinical suspension using early inflammatory markers including $\mathrm{C}$ reactive protein $(\mathrm{CRP})$ or procalcitonin (PCT) [3].

PCT, a peptide from calcitonin superfamily, is a significant diagnostic and prognostic tool for infection [4].
(MELD), Child-pough score (CPS), CRP and PCT. Presepsin cutoff $\geq 1205 \mathrm{pg} / \mathrm{ml}$ could predict infection at sensitivity $83.8 \%$, specificity $93 \%$ and accuracy $88.7 \%$. Resistin cutoff $\geq 21 \mathrm{ng} / \mathrm{ml}$ could predict infection at sensitivity $64.6 \%$, specificity $68.4 \%$ and accuracy $66.7 \%$. Adding CRP to PCT or presepsin increased sensitivity to $99 \%$, specificity $73.7 \%$, and accuracy $85.4 \%$. Adding presepsin to PCT or resistin increased sensitivity to $94.9 \%$. Yet combined presepsin and PCT had higher specificity than combined presepsin and resistin.

Conclusion: Presepsin has comparable diagnostic performances to CRP and PCT for bacterial infection in decompensated cirrhosis while resistin has poor sensitivity and specificity. Adding presepsin to CRP yields the same diagnostic performance as combined CRP and PCT. So, combining any of them to CRP helps to early diagnose bacterial infection in those patients.

Nevertheless, its level may increase in renal failure, a common complication of cirrhosis, in absence of infection due to its low molecular weight that makes it liable to be filtered across the basal glomerular membrane [5]. CRP is supposed to be a good early biomarker for infection [6]. Owing to presence of varied cutoff values stated by former studies included decompensated cirrhotic patients, CRP is unreliable to be depended upon for diagnosis of infection in such patients [6]. Besides, the CRP along with other acute phase reactants are produced in liver. Consequently, in advanced liver disease, CRP level may be unexpectedly low despite the 
presence of bacterial infection [7]. Systemic inflammation that portrays advanced liver disease, can lead to false elevation of CRP even in absence of infection [8].

Cluster of differentiation 14 (CD14) is a multitask glycoprotein released on the exterior of macrophages and neutrophils. Gram-negative bacterial lipopolysaccharide (LPS) and lipopolysaccharide binding protein (LBP) complex attached to it to result in production of CD14-LPS-LBP complex. It is consequently expelled into circulation where inflammatory serum proteases cleave it ending in $\mathrm{N}$-terminal fraction protein called presepsin [9].

Resistin, an insulin resistance-modulating hormone, is secreted by adipocytes and macrophages. It has a novel proinflammatory function that enhances the neutrophil response to LPS stimulation. Elevated serum levels of resistin were detected in severe sepsis and septic shock [10-11]. Besides, in liver cirrhosis, resistin positively correlates with disease stage, and negatively correlates with survival [12].

Hence, this study aimed to assess performance of presepsin and resistin in diagnosis of infection compared with $\mathrm{C}$ reactive protein (CRP) and procalcitonin (PCT) among patients with decompensated cirrhosis.

\section{MATERIALS AND METHODS}

Type, time and pace of the study: A crosssectional study was applied in Internal Medicine hospital, Zagazig University. All cirrhotic patients admitted with signs of decompensation from September 2019 to March 2020 were included in the study.

\section{Case definition:}

Decompensation was outlined by presence of any one of the following either recently-developed or deteriorating preexisting ascites, Upper or lower GI bleeding related to portal hypertension, overt hepatic encephalopathy, AKI (increase in serum creatinine ( $\mathrm{sCr}$ ) levels $\geq 0.3 \mathrm{mg} / \mathrm{dl}$ within $48 \mathrm{~h}$; or a percentage increase $\mathrm{sCr} \geq 50 \%$ from baseline which is known, or presumed, to have occurred within the prior 7 days) or jaundice (total serum bilirubin $>3 \mathrm{mg} / \mathrm{dl}$ ) [13-14].
Diagnosis of infections was according to the following ${ }^{(15)}$ :

i) Spontaneous bacterial peritonitis (SBP) and spontaneous empyema (SE): polymorphonuclear cell count in ascitic and pleural fluid $>250 \mathrm{~mm}^{3}$.

ii) Spontaneous bacteraemia (SB): positive blood cultures without an overt cause of bacteraemia.

iii) Urinary tract infections (UTI): (>10 leukocytes per high-power field in urine and positive urine culture or uncountable $(>500)$ leucocytes per field even without positive cultures).

iv) Respiratory and other types of infections were defined according to conventional criteria.

\section{Study tools:}

1. Complete history taking

2. Comprehensive clinical examination: to detect signs of decompensation and infection, and to identify both Child-pough and MELD scores.

The Child-Pugh scoring system was intended to predict mortality in cirrhotic patients. Through which, patients were categorized as following: Child A, B and C which reflect good, moderately impaired hepatic function and advanced hepatic dysfunction respectively [16]. Pugh et al. [17] modified that scoring system by, substituting Prothrombin time for clinical nutrition status (Table 1).

Table (1): Child Pugh Turcotte (CPT) classification [17]

\begin{tabular}{|l|c|c|c|}
\hline \multicolumn{1}{|c|}{ Points } & 1 & 2 & 3 \\
\hline Encephalopathy & Absent & $\begin{array}{l}\text { Medically } \\
\text { controlled }\end{array}$ & $\begin{array}{c}\text { Poorly } \\
\text { controlled }\end{array}$ \\
\hline Ascites & Absent & $\begin{array}{l}\text { Medically } \\
\text { controlled }\end{array}$ & $\begin{array}{c}\text { Poorly } \\
\text { controlled }\end{array}$ \\
\hline $\begin{array}{l}\text { Bilirubin } \\
\text { (mg/dL) }\end{array}$ & $<2$ & $2-3$ & $>3$ \\
\hline Albumin (g/dL) & $<3.5$ & $2.8-3.5$ & $<2.8$ \\
\hline PT/INR & $<1.7$ & $1.7-2.2$ & $>2.2$ \\
\hline
\end{tabular}

Interpretation: Class-A: 5-6 points; Class-B: 79 points; Class- C: $10-15$ points

The Model for End-stage Liver Disease (MELD) score was a simple and more objective hepatic score. This score included two hepatic (serum bilirubin and one international normalized ratio) and one renal (serum creatinine) variables, 
highlighting the prognostic importance of the interactions between liver and renal functions in cirrhotic patients [18]

It is calculated according to the following formula:[19]

MELD $=3.78 \times \ln [$ serum bilirubin $(\mathrm{mg} / \mathrm{dL})]+$ $11.2 \times \ln [\mathrm{INR}]+9.57 \times \ln [$ serum creatinine $(\mathrm{mg} / \mathrm{dL})]+6.43$

MELD scores are reported as whole numbers, so the result of the equation above is rounded.

\section{Laboratory investigations}

Blood samples were withdrawn to assess Complete blood count (CBC), liver, kidney function test, CRP, PCT, presepsin and resistin.

Blood cultures, urine analysis and culture and also ascitic fluid neutrophil count and ascitic fluid culture to diagnose infection

4. Radiological investigation: including chest $x$ ray and abdominal ultrasonography.

\section{Statistical analysis:}

Data analysis was performed using the software SPSS (Statistical Package for the Social Sciences) version 20. Quantitative variables were described using their means and standard deviations. Categorical variables were described using their absolute frequencies and to compare the proportion of categorical data, chi square test was used when appropriate. Kolmogorov-Smirnov (distribution-type) and Levene (homogeneity of variances) tests were used to verify assumptions for use in parametric tests. To compare means of two groups, independent sample t test (for normally distributed data) and Mann Whitney test (for not normally distributed data) were used. To compare medians of more than two groups, Kruskal Wallis test was used. Spearman correlation coefficient was used to measure correlation between two continuous nonparametric variables. ROC curve was used to determine best cutoff of the studied parameters in diagnosis of certain health problem. The level statistical significance was set at 5\% $(P<0.05)$.

\section{RESULTS}

Mean age of the studied patients was 54.089 years. Two thirds of all patients were males with statistically non-significant relation between presence of infection and either age or gender.
Ascites significantly prevailed in patients with infection $(52.5 \%)$ than those without $(37.7 \%)$. Bleeding, encephalopathy and jaundice did not differ significantly between both groups (22.3\%, $9.1 \%$ and $53.5 \%$ respectively) in patients with infection versus $(22.2 \%, 9.1 \%$ and $54 \%)$ in those without infection (Table 2).

Child-pough and MELD scores were significantly higher among those with infection (mean CPS for infected patients was $13.768 \pm 1.067$ versus $11.553 \pm 1.205$ in non-infected patients) while mean MELD for infected patients was $29.354 \pm$ 6.667 versus $26.412 \pm 6.513$ in non-infected patients. INR was significantly higher in infected patients. Serum albumin, bilirubin and creatinine did not differ significantly among the studied groups (Table 2).

Concerning CRP, procalcitonin, presepsin and resistin, all were significantly higher in infected groups. Mean CRP, PCT, presepsin and resistin among cases were $11.33 \mathrm{mg} / \mathrm{dL}, 1.246 \mathrm{ng} / \mathrm{mL}$, $135.179 \mathrm{pg} / \mathrm{mL}$ and $27.151 \mathrm{ng} / \mathrm{mL}$ respectively (Table 2).

Regarding type of bacterial infections, $26.3 \%$ had urinary tract infection (UTI), 33.3\% had spontaneous bacterial peritonitis, $19.2 \%$ had pneumonia, $14.1 \%$ had skin and soft tissue infections while $7.1 \%$ had multiple site infections (Figure 1)

On examining relation between presepsin and resistin and type of infections, statistically nonsignificant association was detected (Table 3 ).

Both presepsin and resistin significantly positively correlated with MELD and CPT scores, CRP and procalcitonin. Presepsin and resistin positively correlated to each other (Table 4). There is significant negative correlation between presepsin and serum creatinine. A significant negative correlation was found between resistin and both serum bilirubin and creatinine (Table 4).

On evaluating performance of each of the studied markers in diagnosis of infection among patients with decompensated cirrhosis, the best cutoff of CRP was $6.5 \mathrm{mg} / \mathrm{dL}$ (AUC; 0.916, sensitivity; $89.9 \%$, specificity $89.5 \%$ and accuracy; $89.7 \%$, $\mathrm{p}<0.05$ ), PCT was $0.585 \mathrm{ng} / \mathrm{mL}$ (AUC 0.923; sensitivity; $82.8 \%$, specificity $81.6 \%$ and accuracy; $82.2 \%, \mathrm{p}<0.05)$, presepsin was 1205 $\mathrm{pg} / \mathrm{mL}$ (AUC 0.905; sensitivity; 83.8\%, specificity $93 \%$ and accuracy; $88.7 \%, \mathrm{p}<0.05)$, resistin was $21 \mathrm{ng} / \mathrm{mL}$ (AUC 0.773; sensitivity; 
$64.6 \%$, specificity $68.4 \%$ and accuracy; $66.7 \%$, $\mathrm{p}<0.05$ ) (Table 5, Figure 2).

Adding CRP to PCT or presepsin increased sensitivity to $99 \%$, specificity $73.7 \%$, PPV $76.6 \%$, NPV 98.8\% and accuracy $85.4 \%$ (Table 6).

While adding presepsin to PCT or resistin increased sensitivity to $94.9 \%$. Yet, sensitivity of combined presepsin and PCT had higher specificity and accuracy $(73.7 \%$, vs $47.4 \% \%)$ than combined presepsin and resistin. However, accuracy of combined presepsin and resistin was higher $(88.7 \%)$ versus $83.6 \%$ in combined presepsin and PCT (Table 6).

Table (2): Baseline data among patients with decompensated cirrhosis with and without infection.

\begin{tabular}{|l|c|c|c|c|}
\hline & $\begin{array}{c}\text { Total } \\
\mathrm{N}=213\end{array}$ & $\begin{array}{c}\text { With infection } \\
\mathbf{N = 9 9}\end{array}$ & $\begin{array}{c}\text { Without infection } \\
\mathbf{N = 1 1 4}\end{array}$ & $\mathbf{p}$ \\
\hline Age (year) & $54.089 \pm 6.958$ & $53.848 \pm 5.263$ & $54.298 \pm 8.167$ & $0.629^{\#}$ \\
\hline Gender; male & $142(66.7 \%)$ & $72(72.7 \%)$ & $70(61.4 \%)$ & $0.08^{\infty}$ \\
\hline Ascites; yes & $95(44.6 \%)$ & $52(52.5 \%)$ & $43(37.7 \%)$ & $0.03^{\infty} *$ \\
\hline Bleeding & $56(26.3 \%)$ & $22(22.2 \%)$ & $34(29.8 \%)$ & $0.209^{\infty}$ \\
\hline Encephalopathy & $13(6.1 \%)$ & $9(9.1 \%)$ & $4(3.5 \%)$ & $0.149^{\infty}$ \\
\hline Jaundice & $126(59.2 \%)$ & $53(53.5 \%)$ & $73(64 \%)$ & $0.127^{\infty}$ \\
\hline CPS & $12.582 \pm 1.59$ & $13.768 \pm 1.067$ & $11.553 \pm 1.205$ & $<0.001^{\# *}$ \\
\hline MELD & $27.779 \pm 6.732$ & $29.354 \pm 6.667$ & $26.412 \pm 6.513$ & $0.001^{\# *}$ \\
\hline INR & $2.147 \pm 0.353$ & $2.354 \pm 0.309$ & $1.968 \pm 0.284$ & $<0.001^{\# *}$ \\
\hline Albumin(g/dL) & $2.366 \pm 0.345$ & $2.312 \pm 0.206$ & $2.412 \pm 0.426$ & $0.029^{\# *}$ \\
\hline Creatinine (mg/dL) & $1.228 \pm 0.16$ & $1.214 \pm 0.159$ & $1.24 \pm 0.161$ & $0.237^{\#}$ \\
\hline Bilirubin (mg/dL) & $3.878 \pm 2.28$ & $3.754 \pm 2.818$ & $3.986 \pm 2.831$ & $0.208^{¥}$ \\
\hline CRP (mg/dL) & $7.282 \pm 5.166$ & $11.33 \pm 4.09$ & $3.763 \pm 2.943$ & $<0.001^{¥ *}$ \\
\hline PCT (ng/mL) & $0.796 \pm 0.616$ & $1.246 \pm 0.539$ & $0.406 \pm 0.361$ & $<0.001^{¥ *}$ \\
\hline Presepsin (pg/mL) & $939.498 \pm 549.899$ & $1351.79 \pm 430.59$ & $581.46 \pm 355.25$ & $<0.001^{¥ *}$ \\
\hline Resistin (ng/mL) & $21.572 \pm 10.74$ & $27.151 \pm 11.033$ & $16.727 \pm 7.739$ & $<0.001^{¥ *}$ \\
\hline
\end{tabular}

${ }^{¥}$ Mann Whitney test

${ }^{\infty}$ Chi Square test

"Independent sample $t$ test

${ }^{*} \mathrm{p}<0.05$ is statistically significant

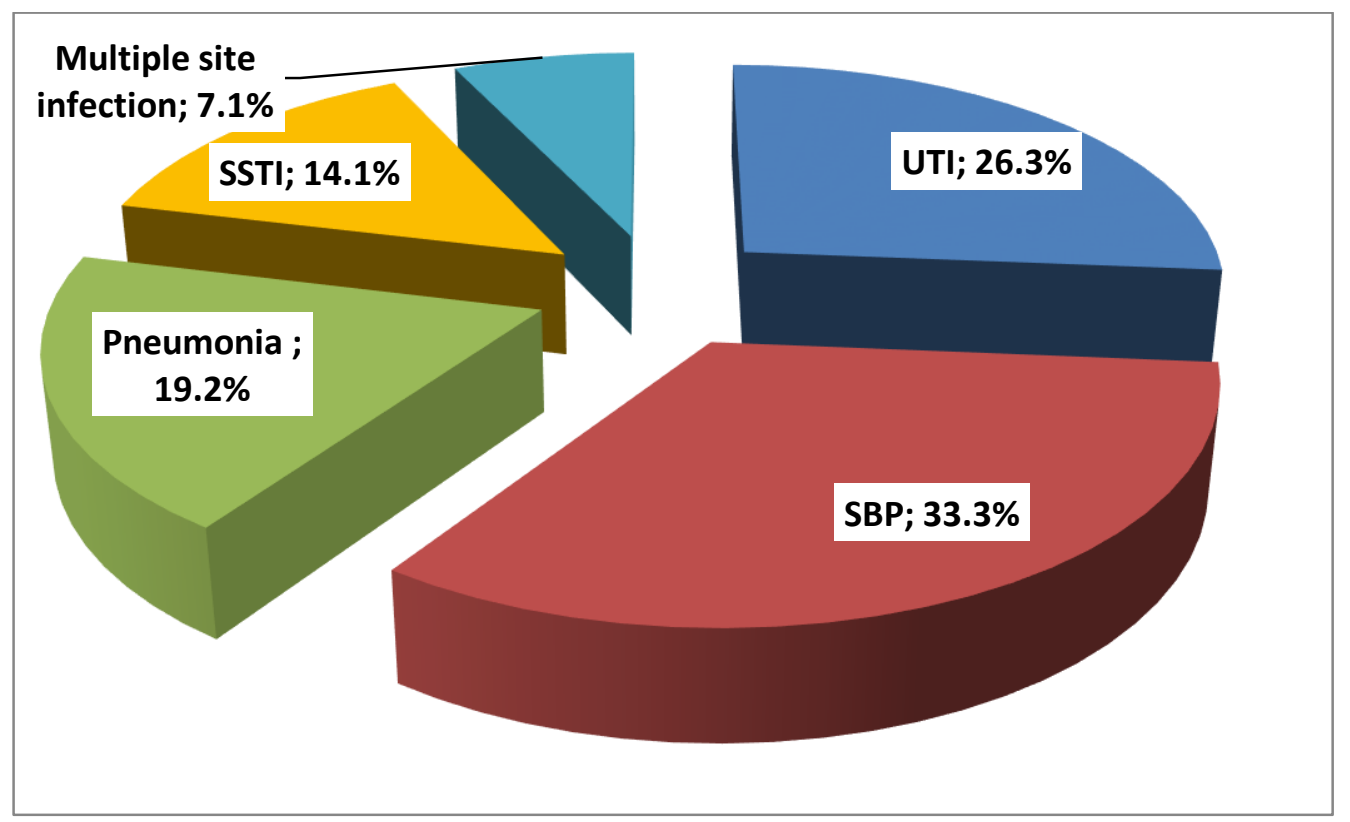

Figure (1). Pie chart showing distribution of patients according to type of infections. 
Table (3): Relation between the studied markers and type of bacterial infections among the studied patients.

\begin{tabular}{|c|c|c|c|c|}
\hline \multirow[t]{2}{*}{ Type of infection } & \multicolumn{2}{|l|}{ Presepsin } & \multicolumn{2}{|c|}{ Resistin } \\
\hline & Median (range) & $\mathbf{p}^{¥}$ & Median (range) & $\mathbf{p}^{¥}$ \\
\hline UTI & $1379(360-2200)$ & \multirow{5}{*}{0.807} & $24(10-50)$ & \multirow{5}{*}{0.49} \\
\hline SBP & $1389(350-2200)$ & & $22(10-55)$ & \\
\hline Pneumonia & $1360(350-2444)$ & & $23.5(10-57)$ & \\
\hline SSTI & $1448(350-2000)$ & & $27(10-45)$ & \\
\hline Multiple site infection & $1440(1210-2000)$ & & $20(7-34)$ & \\
\hline
\end{tabular}

UTI: Urinary tract infection

SSTI: Skin and soft tissue infections

SBP: Spontaneous bacterial peritonitis

¥: Kruskal Wallis test

Table (4): Correlation between presepsin and resistin and the studied parameters.

\begin{tabular}{|l|l|l|l|l|}
\hline \multirow{2}{*}{ Parameters } & Presepsin & Resistin & \multicolumn{2}{l|}{} \\
\cline { 2 - 5 } & $\mathbf{r}$ & $\mathbf{p}$ & $\mathbf{r}$ & $<$ \\
\hline INR & 0.454 & $<0.001^{*}$ & 0.272 & $0.001^{*}$ \\
\hline Albumin(g/dL) & 0.07 & 0.307 & 0.181 & $0.008^{*}$ \\
\hline Creatinine (mg/dL) & -0.148 & $0.031^{*}$ & -0.165 & $0.016^{*}$ \\
\hline Bilirubin (mg/dL) & -0.061 & 0.377 & -0.164 & $0.017^{*}$ \\
\hline MELD & 0.356 & $<0.001^{*}$ & 0.192 & $0.005^{*}$ \\
\hline CPT score & 0.571 & $<0.001^{*}$ & 0.361 & $<0.001^{*}$ \\
\hline CRP (mg/dL) & 0.592 & $<0.001^{*}$ & 0.417 & $<0.001^{*}$ \\
\hline PCT (ng/mL) & 0.617 & $<0.001^{*}$ & 0.402 & $<0.001^{*}$ \\
\hline Presepsin $(\mathbf{p g} / \mathbf{m L})$ & & & 0.409 & $<0.001^{*}$ \\
\hline Resistin $\mathbf{( n g / m L ) ~}$ & 0.409 & $<0.001^{*}$ & & \\
\hline
\end{tabular}

$\mathrm{r}$ Spearman rank correlation coefficient $\quad * \mathrm{p}<0.05$ is statistically significant

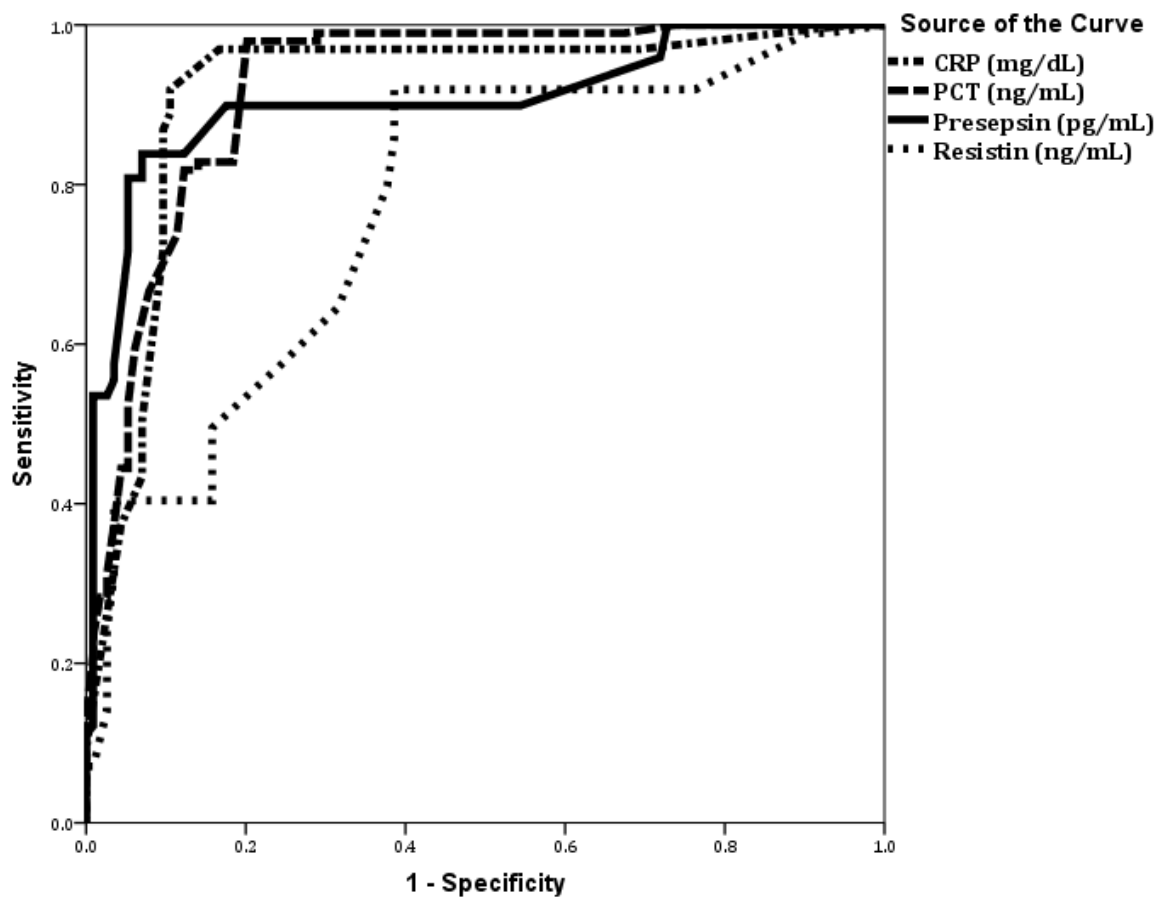

Figure (2). ROC curve showing performance of CRP, PCT, presepsin and resistin in diagnosis of bacterial infection in patients with decompenated cirrhosis. 
Table (5): Performance of the studied markers in detection of infection among patients with decompensated cirrhosis.

\begin{tabular}{|l|c|c|c|c|c|c|c|c|}
\hline & AUC & Cutoff & Sensitivity & Specificity & PPV & NPV & Accuracy & p \\
\hline CRP $(\mathbf{m g} / \mathbf{d L})$ & 0.916 & 6.5 & $89.9 \%$ & $89.5 \%$ & $88.1 \%$ & $91.1 \%$ & $89.7 \%$ & $<0.001^{*}$ \\
\hline PCT (ng/mL) & 0.923 & 0.585 & $82.8 \%$ & $81.6 \%$ & $79.6 \%$ & $84.5 \%$ & $82.2 \%$ & $<0.001^{*}$ \\
\hline Presepsin (pg/mL) & 0.905 & 1205 & $83.8 \%$ & $93 \%$ & $91.2 \%$ & $86.9 \%$ & $88.7 \%$ & $<0.001^{*}$ \\
\hline Resistin (ng/mL) & 0.773 & 21 & $64.6 \%$ & $68.4 \%$ & $64 \%$ & $69 \%$ & $66.7 \%$ & $<0.001^{*}$ \\
\hline
\end{tabular}

AUC: area under curve

$* \mathrm{p}<0.05$ is statistically significant

Table (6): Performance of the studied markers in detection of infection among patients with decompensated cirrhosis.

\begin{tabular}{|l|c|c|c|c|c|}
\hline \multicolumn{1}{|c|}{ Suggested cutoff } & Sensitivity & Specificity & PPV & NPV & Accuracy \\
\hline CRP + PCT & $99 \%$ & $73.7 \%$ & $76.6 \%$ & $98.8 \%$ & $85.4 \%$ \\
\hline CRP + presepsin & $99 \%$ & $73.7 \%$ & $76.6 \%$ & $98.8 \%$ & $85.4 \%$ \\
\hline Presepsin + resistin & $94.9 \%$ & $47.4 \%$ & $61 \%$ & $91.5 \%$ & $88.7 \%$ \\
\hline PCT + presepsin & $94.9 \%$ & $73.7 \%$ & $75.8 \%$ & $94.4 \%$ & $83.6 \%$ \\
\hline
\end{tabular}

NPV Negative predictive value.

\section{DISCUSSION}

The current study revealed that both presepsin and, to a less extent, resistin are reliable markers of bacterial infections in patients with decompensated cirrhosis with comparable diagnostic performance as both CRP and PCT. Combining PCT or presepsin to CRP yield promising diagnostic performance. Choosing which combination can be made upon economic evaluation.

In a prior research by Papp et al. [20], median Presepsin level was $576 \mathrm{pg} / \mathrm{mL}$ which was significantly higher in patients with infection. In their study, they stated that Presepsin was a good predictor of bacterial infection [cutoff $\geq 1207$ ]. It was superior to PCT but fairly lower than CRP.

Joining both CRP and presepsin, at the suggested cutoff, improved the sensitivity and NPV, compared with CRP alone. A similar style was found on combining both CRP and PCT in agreement with the current study. They also stated that cutoff of CRP and PCT were $\geq 39.6 \mathrm{mg} / \mathrm{dL}$ (sensitivity $75 \%$ and specificity $69.1 \%$ ) and 0.48 $\mathrm{ng} / \mathrm{mL}$ (sensitivity $90 \%$ and specificity $74.6 \%$ ) respectively [20].

According to the study by Elefsiniotis et al. [21], baseline presepsin is higher in patients with decompensated cirrhosis even in lack of bacterial infection comparing to its level in patients with compensated disease.
A previous research conveyed that the optimal presepsin cut-off in diagnosis of infection was $1444 \mathrm{pg} / \mathrm{ml}$. At that point, $70 \%$ of the patients were adequately categorized as having infection. At cutoff $\geq 20 \mathrm{ng} / \mathrm{ml}$, resistin can establish infection with $70 \%$ accuracy [22].

Different diagnostic cutoff levels of resistin detecting infections in non-cirrhotic populations were suggested, but most reports stated that it could range from of 400-600 pg/mL [23-24].

Porto-systemic shunts can lead to insulin resistance [25]. Various authors reported that resistin positively correlated with disease stage and negatively with survival $[\mathbf{1 2 , 2 6}]$. In a prior study, resistin almost equaled to other inflammatory markers in the diagnosis of bacterial infections and sepsis [22].

The main limitation of our study is that it was applied in a single center with a relatively small sample size. Presepsin and resistin were not examined against to bacterial translocation markers such as LPS. This was a cross sectional study without any sort of follow up. However, one of strength points was that presepsin and resistin were compared at the same point of time to wellestablished inflammatory markers, CRP and PCT.

\section{CONCLUSION}

Presepsin has comparable diagnostic performances to CRP and PCT for bacterial infection in decompensated cirrhosis while resistin has poor sensitivity and specificity. 
Adding presepsin to CRP yields the same diagnostic performance as combined CRP and PCT. Therefore, combining any of them to CRP helps early diagnosis of bacterial infection in those patients.

Conflict of interest: None declared.

Funding: the research was funded by the authors.

Ethical considerations :An informed verbal consent was obtained from the studied patients. Ethical committee in Faculty of Medicine, Zagazig University, approved the research

\section{REFERENCES}

1. Fernández J, Gustot T. Management of bacterial infections in cirrhosis. J Hepatol 2012; 56(Suppl 1):S1-12.

2. Jalan R, Fernandez J, Wiest R, Schnabl B, Moreau $\mathrm{R}$, Angeli P, et al. Bacterial infections in cirrhosis: a position statement based on the EASL Special Conference 2013. J Hepatol 2014; 60: 1310-1324

3. Lin KH, Wang FL, Wu MS, Jiang BY, Kao WL, Chao HY, et al. Serum procalcitonin and Creactive protein levels as markers of bacterial infection in patients with liver cirrhosis: a systematic review and meta-analysis. Diagn Microbiol Infect Dis 2014;80:72-8.

4. Vijayan AL, Ravindran S, Saikant R, Lakshmi S, Kartik R. Procalcitonin: apromising diagnostic marker for sepsis and antibiotic therapy. $J$ Intensive Care 2017; 5(August):51.

5. Lee WS, Kang DW, Back JH, Kim HL, Chung JH, Shin BC. Cutoff value of serumprocalcitonin as a diagnostic biomarker of infection in end-stage renal diseasepatients. Korean J Intern Med 2015; 30:198-204

6. Tsiakalos A, Karatzaferis A, Ziakas P, Hatzis G. Acute-phase proteinsas indicators of bacterial infection in patients with cirrhosis. Liver Int 2009; 29(November (10)):1538-42.

7. Pieri G, Agarwal B, Burroughs AK. C-reactive protein and bacterial infection incirrhosis. Ann Gastroenterol 2014; 27:113-20.

8. Papp M, Vitalis Z, Altorjay I, Tornai I, Udvardy M, Harsfalvi J. Acute phase pro-teins in the diagnosis and prediction of cirrhosis associated bacterial infection. Liver Int 2011; 32:603-11.
9. Yegashi Y, Shirakawa K, Sato N, Suzuki Y, Kojika M, Imai S. Evaluation of a newly identified soluble CD14 subtype as a marker for sepsis. $J$ Infect Chemother 2005; 11:234-8.

10. Jiang S, Park DW, Tadie JM, Gregoire M, Deshane J, Pittet JF, et al. Humanresistin promotes neutrophil pro-inflammatory activation, neutrophil extra-cellular trap formation, and increases severity of acute lung injury. J Immunol 2014; 192:4795-803.

11. Macdonald SP, Stone SF, Neil CL, van Eeden PE, Fatovich DM, Arendts G, et al. Sustained elevation of resistin, NGAL and IL-8 are associated with severe sep-sis/septic shock in the emergency department. PLoS One 2014; 9:e110678.

12. Yagmur E, Trautwein C, Gressner AM, Tacke F. Resistin serum levels areassociated with insulin resistance, disease severity, clinical complications, and prognosis in patients with chronic liver diseases. Am J Gastroenterol 2006; 101: 1244-52.

13. Angeli $\mathrm{P}$, Ginès $\mathrm{P}$, Wong $\mathrm{F}$, Bernardi $\mathrm{M}$, Boyer TD, Gerbes A. Diagnosis and management of acute kidney injury in patients with cirrhosis: revised consensus recommendations of the International club of ascites. J Hepatol 2015; 62:968-74.

14. European Association for the Study of the Liver. EASL clinical practice guide-lines for the management of patients with decompensated cirrhosis. J Hepatol 2018; 69:406-60.

15. Horan TC, Andrus M, Dudeck MA. CDC/NHSN surveillance definition of healthcare-associated infection and criteria for specific types of infections in the acutecare setting. Am J Infect Control 2008; 36(June (5)):309-32.

16. Child CG, Turcotte JG. Surgery and portal hypertension. Major Probl Clin Surg 1964;1:1-85

17. Pugh RN, Murray-Lyon IM, Dawson JL, Pietroni MC, Williams R. Transection of the oesophagus for bleeding oesophageal varices. Br J Surg 1973 Aug; 60(8):646-9.

18. Aiello FI, Bajo M, Marti F, Gadano A, Musso CG. Model for End-stage Liver Disease (MELD) score and liver transplant: benefits and concerns. $A M E$ Med J 2017;2:168.

19. Kamath, Patrick S; Kim, W. Ray. "The model for end-stage liver disease (MELD)". Hepatology 2007. 45 (3):797805. 
20. Papp M, Tornai T, Vitalis Z, Tornai I, Tornai D, Dinya $T$, et al. Presepsin teardown - pitfalls of biomarkers in the diagnosis and prognosis of bacterial infection in cirrhosis. World $J$ Gastroenterol 2016 November 7; 22(41): 91729185.

21. Elefsiniotis I, Tsakiris SA, Barla G, Tasovasili A, Vrachatis D, Mavrogiannis C. Presepsin levels in cirrhotic patients with bacterial infections and/or portal hypertension-related bleeding, presenting with or without acute kidney injury. Ann Gastroenterol 2018; 31(September-October (5)):604-12

22. Fischer P, Grigorasa C, Bugariua A, NicoaraFarcaua O, Stefanescub H, Beneab A, et al. .Are presepsin and resistin better markers for bacterial infection in patients with decompensated liver cirrhosis? Digestive and Liver Disease 2019, 51: 1685-1691
23. Shozushima T, Takahashi G, Matsumoto N, Kojika M, Okamura Y, Endo S. Usefulness of presepsin (sCD14-ST) measurements as a marker for the diagnosis and severity of sepsis that satisfied diagnostic criteria of systemic inflammatory response syndrome. $J$ Infect Chemother 2011; 17: 764-769

24. Ulla M, Pizzolato E, Lucchiari M, Loiacono M, Soardo F, Forno D, et al. Diagnostic and prognostic value of presepsin in the managementof sepsis in the emergency department: a multicenter prospective study. Crit Care 2013; 17: R168

25. Bosch J, Gomis R, Kravetz D, Casamitjana R, Terés J, Rivera F, et al. Role of spontaneous portalsystemic shunting in hyperinsulinism of cirrhosis. Am J Physiol 1984; 247: G206-12.

26. Kakizaki S, Sohara N, Yamazaki Y, Horiguchi N, Kanda D, Kabeya K, et al. Elevated plasma resistin concentrations in patients with liver cirrhosis. $J$ Gastroenterol Hepatol 2008; 23:73-7.. 